\title{
Evidence for Tissue-specific Activation of Renal Angiotensinogen mRNA Expression in Chronic Stable Experimental Heart Failure
}

\author{
Heribert Schunkert, * Julie R. Ingelfinger, * Alan T. Hirsch, ${ }^{*}$ Shiow-Shih Tang, * \\ Sheldon E. Litwin, ${ }^{*}$ Chris E. Talsness, ${ }^{*}$ and Victor J. Dzau * \\ *Cardiovascular Research Center and the Division of Cardiovascular Medicine, Stanford University School of Medicine, Stanford, \\ California 94305-5246; Molecular and Cellular Vascular Research Laboratory, Division of Vascular Medicine, Brigham and Women's \\ Hospital, Harvard Medical School, Boston, Massachusetts 02115; and ${ }^{\ddagger}$ Division of Cardiovascular Medicine, \\ Beth Israel Hospital, Harvard Medical School, Boston, Massachusetts 02215
}

\section{Abstract}

The intrarenal renin-angiotension system (RAS) may contribute to the pathophysiology of heart failure by the generation of angiotensin II at local sites within the kidneys. Angiotensin II may directly influence renal hemodynamics, glomerular contractility, and tubular sodium reabsorption, thereby promoting sodium and fluid retention in this syndrome. In the present study, we examined components of the circulating RAS as well as the intrarenal expressions of renin and angiotensinogen mRNA in rats with stable compensated heart failure (HF) 12 wk after experimental myocardial infarction. Renal angiotensinogen mRNA level in vehicle-treated HF rats increased $47 \%$, as compared with sham control rats $(P=0.001)$. The increase in angiotensinogen mRNA levels was more pronounced in animals with medium $(46 \%, P<0.05)$ and large $(66 \%, P<0.05)$ infarcts than in those with small infarcts $(31 \%, P=N S)$. There were no differences in liver angiotensinogen mRNA, circulating angiotensinogen, angiotensin II, plasma renin concentration (PRC), kidney renin content (KRC), and renal renin mRNA level between sham and $\mathrm{HFv}$. In addition, in a separate group of rats with heart failure, we demonstrated that renal angiotensin II concentration increased twofold $(P<0.05)$ as compared with that of age-matched sham operated controls. A parallel group of heart failure rats ( $\mathrm{HFe}, n=11$ ) was treated with enalapril ( $25 \mathrm{mg} / \mathrm{kg}$ per d) in drinking water for 6 wk before these measurements. Blood pressure decreased significantly during treatment (91 vs. $103 \mathrm{~mm} \mathrm{Hg}, P<0.05)$. Enalapril treatment in HF rats increased renin $m$ RNA level $(2.5$-fold, $P<0.005)$, KRC (5.6-fold, $P=0.005)$, and PRC (15.5-fold, $P<0.005)$. The increase in renal angiotensinogen mRNA level observed in HFv rats was markedly attenuated in enalapril treated $H F$ rats ( $P$ $<0.001$ ), suggesting a positive feedback of angiotensin II on renal angiotensinogen synthesis. These findings demonstrate an activation of intrarenal RAS, but no changes in the circulating counterpart in this model of experimental heart failure, and

Address correspondence to Victor J. Dzau, M.D., Falk Cardiovascular Research Center, Stanford University School of Medicine, 300 Pasteur Drive, Stanford, CA 94305-5246.

Heribert Schunkert's present address is Medizinische Klinik II, University of Regensburg, 8400 Regensburg, Germany. Dr. Ingelfinger's address is WACC-709, Massachusetts General Hospital, Boston, MA 02114.

Received for publication 29 October 1990 and in revised form 10 February 1992.

J. Clin. Invest.

(C) The American Society for Clinical Investigation, Inc.

$0021-9738 / 92 / 10 / 1523 / 07 \quad \$ 2.00$

Volume 90, October 1992, 1523-1529 they support the concept that the intrinsic renal RAS may contribute to the pathophysiology in this syndrome. (J. Clin. Invest. 1992. 90:1523-1529.) Key words: renin - renin-angiotensin system • enalapril • gene expression

\section{Introduction}

The kidneys contribute to the pathophysiology of heart failure $(\mathrm{HF})^{1}$ by enhanced sodium and fluid retention $(1,2)$. Several neurohormonal mechanisms, including the renin-angiotensin (RAS) and sympathetic nervous systems, participate in the adaptive responses of the kidney in this disease state $(3,4)$. Angiotensin II is known to decrease renal blood flow, to increase efferent arteriolar resistance and filtration fraction, as well as to enhance sodium reabsorption (5-7). It is established that circulating renin and angiotensin levels are elevated during acute cardiac decompensation $(3,8,9)$. However, in the chronic stable stage of experimental $(3,10-12)$ or clinical ( 8 , 13) heart failure, plasma levels of renin and angiotensin II may not be increased. Although the circulating RAS is not activated, alterations in renal function may be corrected by angiotensin converting enzyme inhibition $(14,15)$.

In addition to circulating factors, local or paracrine mechanisms may be involved in the regulation of renal function during chronic HF. For example, increased renal prostaglandins preserve renal blood flow when cardiac output is low (16). There is increasing evidence that the kidney also contains a local RAS that may operate independently of the circulating RAS (17-21). The expressions of renin and angiotensinogen genes in the kidney have been demonstrated $(20,22)$. In addition, the presence of angiotensin converting enzyme (ACE) in the brush border of proximal tubules has been well documented (18). Thus, the presence of each of the components of the RAS suggests that the kidney is capable of synthesizing angiotensin II locally (23).

The goal of the present investigation was to study the relative status of circulating and intrarenal RAS in experimental heart failure. The components of the intrarenal RAS were studied by examining renal renin concentration, renin and angiotensinogen mRNA levels, as well as angiotensin II concentration. Determinations of plasma renin, angiotensinogen, and angiotensin II concentrations were used to assess the status of the circulating RAS. Our results demonstrated that renal angiotensinogen mRNA expression was increased in chronic

1. Abbreviations used in this paper: $\mathrm{ACE}$, angiotensin converting enzyme; HF, heart failure; HFe, enalapril-treated heart failure; HFv, vehicle-treated heart failure; $\mathrm{KRC}$, kidney renin content; PRC, plasma renin concentration; RAS, renin-angiotensin system; TFA, trifluoracetic acid. 
compensated heart failure, whereas the activity of the circulating RAS was normal. The feedback regulation of these components of angiotensin II biosynthesis in HF was further assessed by chronic blockade of the system by the ACE inhibitor, enalapril. Long-term enalapril treatment, which increased renal renin mRNA and enzyme levels, normalized renal angiotensinogen mRNA levels in rats with experimental heart failure.

\section{Methods}

Male Sprague-Dawley rats (200-250 g) underwent left coronary artery ligation or sham operation at 2 mo of age. Animals were allowed free access to a $0.4 \%$ sodium diet (regular Purina rat chow; Ralston-Purina, St. Louis, MO) and water was provided ad lib. These studies were approved by the Institutional Standing Committee on Animals and performed according to U. S. Public Health Service guidelines.

Experimental heart failure. The coronary ligated rat model of chronic compensated heart failure was prepared for study using standard methods $(24,25)$. The left anterior thorax was dissected during ether anesthesia, the heart was exteriorized, and the left coronary artery was ligated with 6-0 prolene suture. Surgical attrition from this procedure is $\sim 40 \%$. 1 wk postoperatively, surviving animals were subgrouped by a modified 10 -lead electrocardiogram into sham or myocardial infarction (HF) study cohorts. Group stratification was in all cases confirmed postmortem by quantitative left ventricular histopathology. Previous studies demonstrated that this rat model exhibited progressive ventricular dilatation and renal sodium retention without evidence of acute decompensation (14, 25-27).

Blood pressure studies. Indirect systolic blood pressure was determined by the tail-cuff method 6 and 11 wk after surgery. Reported values represent the mean of recordings performed on three consecutive days. The correlation of indirect blood pressures with direct pressure measurements in our laboratory achieves a correlation coefficient $r=0.98$, and is comparable with data reported in the literature (28).

Morphometric analysis of infarct size. The left ventricle was sectioned transversely in at least five planes, stained with Masson's trichrome and $\mathrm{H} \& \mathrm{E}$, and projected for quantitative planimetry of infarct size. The mean of the endocardial and epicardial scar circumferences was compared to total left ventricular circumference to calculate total infarct size (percentage). Using this type of assessment, heart failure animals were stratified into groups by infarct size: small (10$25 \%, n=8)$, medium $(26-40 \%, n=7)$, and large infarcts $(41-55 \%, n$ $=5$ ). All infarctions were transmural and involved only the free wall of the left ventricle.

Protocol. The status of plasma and tissue RAS was compared in 17 sham and 20 heart failure animals killed 3 mo after surgery. A parallel group of heart failure animals $(n=11)$ were housed in individual cages and received enalapril $(25 \mathrm{mg} / \mathrm{kg}$ per d) in drinking water. ACE-inhibition was initiated $6 \mathrm{wk}$ postoperatively and continued for $6 \mathrm{wk}$ before death. The concentration of enalapril in drinking water was individually calculated to provide the same daily dose of the drug, based on the drinking behavior of each rat.

The RAS in the kidney was studied by measuring renal renin concentration, as well as renal renin and angiotensinogen mRNA levels. Furthermore, hepatic angiotensinogen mRNA levels were examined, since the liver is the main source of circulating angiotensinogen. Plasma renin activity, as well as plasma angiotensinogen levels were studied in all the animals. Plasma angiotensin II levels were measured in a subgroup of 11 sham and $12 \mathrm{HF}$ animals. To examine if the changes in renal angiotensinogen mRNA levels were accompanied by parallel alterations of renal angiotensin II concentrations, eight $\mathrm{HF}$ rats and six age-matched sham operated controls were studied six weeks after surgery. All biochemical and molecular determinations of RAS components were performed by investigators who were blinded for the results of left ventricular histopathology.

Biochemical studies. Plasma renin concentration (PRC) assay was performed with rat plasma obtained from blood collected in ice-chilled tubes containing sodium EDTA (final concentration of $4 \mathrm{mM}$ ).
Plasma was incubated with excess exogenous substrate at $37^{\circ} \mathrm{C}, \mathrm{pH}$ 7.4 , with protease inhibitors $(3.4 \mathrm{mM}$ 8-hydroxyquinolone sulfate, $0.25 \mathrm{mM}$ EDTA, $0.1 \mathrm{mM}$ PMSF, $1.6 \mathrm{mM}$ dimercaprol, and $5 \mathrm{mM}$ sodium tetrathionate [NaTT]) for $1-3 \mathrm{~h}$. The source of substrate was renin-free plasma (diluted 1:3) from sheep nephrectomized $48 \mathrm{~h}$ before plasma collection. The angiotensin I generated was measured by RIA.

Kidney renin concentration was similarly determined. The tissue was homogenized in $0.1 \mathrm{M}$ Tris $\mathrm{HCl}$ buffer, $\mathrm{pH} 7.4$, containing the above inhibitors plus $0.1 \%$ Triton-X 100 . After centrifugation to remove debris, the supernatant was assayed as described above. Tissue protein concentration was determined by the method of Bradford (29) using the Bio-Rad reagent (Bio-Rad Laboratories, Richmond, CA).

Plasma angiotensinogen concentration was determined as previously described (22). Plasma was incubated with excess exogenous renin at $37^{\circ} \mathrm{C}, \mathrm{pH} 6$, with protease inhibitors $(3.4 \mathrm{mM}$ 8-hydroxyquinolone sulfate, $0.25 \mathrm{mM}$ EDTA, $0.1 \mathrm{mM}$ PMSF, $5 \mathrm{mM}$ sodium tetrathionate, $1.6 \mathrm{mM}$ dimercaprol) for 1-3 $\mathrm{h}$ until all the angiotensinogen was completely converted to angiotensin $I$. The source of renin was partially purified mouse submandibular gland renin. Plasma angiotensinogen level was estimated from the total angiotensin I generated upon complete exhaustion of the substrate by renin and expressed as nanograms Ang I equivalent per milliliter per hour.

Plasma for angiotensin II assay was obtained from blood collected in ice-chilled tubes containing EDTA, PMSF, and NaTT in the concentrations as noted above. Each sample was immediately centrifuged in the cold $\left(4^{\circ} \mathrm{C}\right)$ and snap-frozen in liquid nitrogen. For kidney angiotensin II determination, the tissue was homogenized and extracted in 0.1 Tris $\mathrm{HCl}, \mathrm{pH} 7.4$, plus the above peptidase inhibitors. Plasma or kidney extract was then partially purified using a Sep Pak column (Waters Chromatography Div., Milford, MA); the column was conditioned with $3 \mathrm{ml}$ methanol and $10 \mathrm{ml} 0.01 \%$ trifluoracetic acid (TFA) before the sample was loaded and washed with $10 \mathrm{ml} 0.01 \%$ TFA. Peptides were eluted with $3 \mathrm{ml} 80 \%$ acetonitrile in $0.01 \%$ TFA and lyophilized. Recovery of angiotensin II from this procedure was $95 \%$. Angiotensin II was measured by RIA using a commercial rabbit angiotensin II antibody (Arnel Products, NY) and a donkey anti-rabbit antibody (Amersham Corp., Arlington Heights, IL) for magnetic separation of bound and unbound tracer.

RNA isolation and hybridizations. Rats were killed by decapitation. Organs were snap-frozen in liquid nitrogen within $3 \mathrm{~min}$. All tissue was stored at $-80^{\circ} \mathrm{C}$ until used. Homogenization of various tissues was carried out in $4 \mathrm{M}$ guanidine thiocyanate, $0.5 \%$ sodium- $n$ lauryl sarcosine, $25 \mathrm{mM}$ sodium citrate, $0.1 \mathrm{M} \beta$-mercaptoethanol mercaptoethanol, and $2 \mathrm{M} \mathrm{CsCl}$; and RNA was pelleted by ultracentrifugation (30). The RNA was resuspended in $0.2 \mathrm{M}$ sodium acetate, $\mathrm{pH} 5.5$, rocked at $4^{\circ} \mathrm{C}$ for $1 \mathrm{~h}$, and precipitated in $2 \mathrm{vol}$ of ethanol. The precipitated RNA was dissolved in water and the amount quantitated by absorbance at $260 \mathrm{~nm}$ in duplicate. Comparison of relative mRNA levels were made in reference to the same amount of total RNA applied per sample. Efficiency of transfer was confirmed by ethidium bromide stain and examined pre- and posttransfer. For Northern blot analysis, aliquots of total RNA were run using the formaldehyde-agarose method (31).

Gels were transblotted onto nylon filters by capillary action with 10 $\times$ standard saline citrate $(\mathrm{SSC})(1 \times$ SSC equals $0.15 \mathrm{M}$ sodium chloride, $0.015 \mathrm{M}$ sodium citrate, $\mathrm{pH} 7.0$ ) for $16 \mathrm{~h}$, after which they were cross-linked by ultraviolet light. After prehybridization for $4 \mathrm{~h}$, the blots were hybridized overnight in a buffer to which alpha ${ }^{32} \mathrm{P}-\mathrm{cDNA}$ probes were added ( 31 ). For additional quantitation, slot blot hybridization analyses were performed. Samples were formaldehyde denatured and then serially diluted in $15 \times \mathrm{SSC}$. Three concentrations from each sample $(8,4,2 \mu \mathrm{g})$ were blotted in duplicate to nylon filters using a slot blot apparatus (Schleicher \& Schuell, Inc., Keene, NH), after which blots were hybridized as above.

After hybridization, blots were washed in $0.2 \times$ SSC with $0.1 \%$ sodium dodecyl sulfate at room temperature for $10 \mathrm{~min}$, then three times at $65^{\circ} \mathrm{C}$ for $30 \mathrm{~min}$. Blots were exposed for $5 \mathrm{~d}$ to $\mathrm{x}$-ray film (Kodak XAR; Eastman Kodak, Rochester, NY). All studies of angio- 
tensinogen mRNA were performed with a full length rat liver angiotensinogen probe ( $p$ Rang 1650). For renin mRNA determinations, we used renin cDNA pDD 1D-2, a full length mouse submaxillary gland renin cDNA which readily crosshybridizes with rat renal renin mRNA (22). To control for possible sample variability, identical slot blots were performed and hybridized with a control cDNA probe ( $\beta$-actin).

Quantification of $m R N A$. Autoradiograms generated by slot blots were scanned with microdensitometer (Pharmacia LKB, Piscataway, $\mathrm{NJ}$ ) with background set to zero for each autoradiograph. Regression lines were calculated from the integral values obtained by scanning the serial concentrations of each sample. The relative signals of the specific mRNA were estimated from the slope of the regression line, and only $r$ values $>0.90$ were accepted. Slopes of specific mRNA for each condition were compared as relative ratios. Sufficient material was available to study specimens with multiple sample applications. Four standard RNA samples from adult male liver and kidney were run on all slot blots as interblot reference standards. Our intra- and interblot coefficient of variations were 8 and $9 \%$, respectively.

Statistical analysis. All data are presented as mean \pm SE. Average slopes of slot blot autoradiographs were directly compared by Student's unpaired $t$ tests. Two-way analysis of variance combined with Fisher's exact test for posthoc analyses were used for multiple comparisons in case of three or more comparisons between groups. The relationships between infarct size, blood pressure, or renal angiotensin II concentration and renal angiotensinogen mRNA level were determined using rank correlation analysis (Spearman's rho). Significance was accepted for $P<0.05$.

\section{Results}

In this investigation, we examined the activity of the circulating and intrarenal renin angiotensin systems in rats with chronic stable experimental heart failure studied late $(3 \mathrm{mo}$ ) after coronary ligation. Previous studies demonstrated that this rat model exhibited impaired ventricular function, progressive ventricular dilatation, and renal sodium retention (14, 25-27). There were no deaths in any cohort during the observation period. Disease severity was assessed by quantitative histological examination of serial cross sections of the left ventricle. The average infarct size was $32 \pm 3 \%$.

Untreated chronic stable HF animals displayed a higher renal angiotensinogen mRNA level than sham operated control rats (as shown in representative Northern blot, Fig. 1). To examine the difference quantitatively, multiple slot blot analyses were performed. In animals with heart failure $(n=20)$ renal angiotensinogen mRNA level increased by $47 \%$ on average as compared to shams $(n=17 ; P=0.001)$ (Fig. 2$)$. Heart failure animals were subdivided to groups with small $(10-25 \%, n$ $=8$ ), medium $(26-40 \%, n=7)$, and large infarcts $(41-55 \%, n$ $=5)$. Renal angiotensinogen mRNA in rats with small infarcts increased slightly ( $31 \% ; P=\mathrm{NS}$ ) but was not statistically different from sham controls. We observed a greater increase of renal angiotensinogen mRNA levels in animals with larger infarcts, especially those rats whose myocardial infarction was $>25 \%$ of the left ventricular circumference. The increase in renal angiotensinogen mRNA was $46 \%(P<0.05)$ in animals with medium and $66 \%(P<0.05)$ in animals with large infarcts as compared with sham controls. Thus, there was a significant correlation between myocardial infarct size and renal angiotensinogen mRNA levels $(r=0.51, P=0.001)$ : Liver angiotensinogen, the major source of plasma angiotensinogen, was examined to determine whether renal angiotensinogen induction in chronic heart failure is a tissue-specific phenomenon. Interestingly, no changes in hepatic angiotensinogen mRNA
A

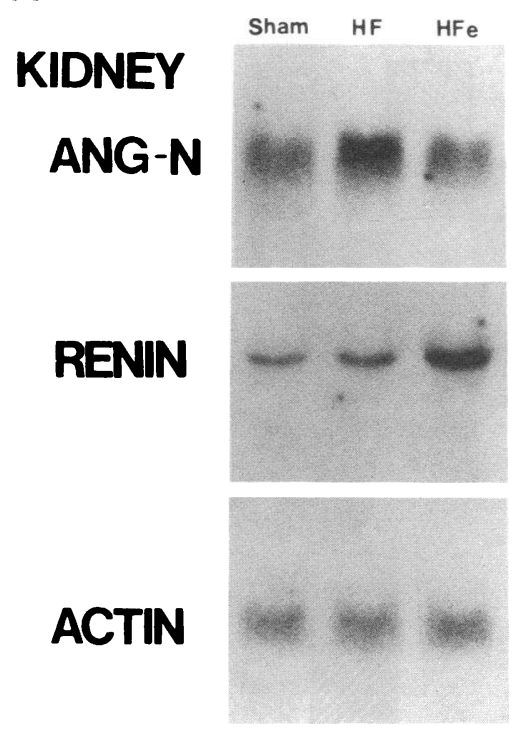

B
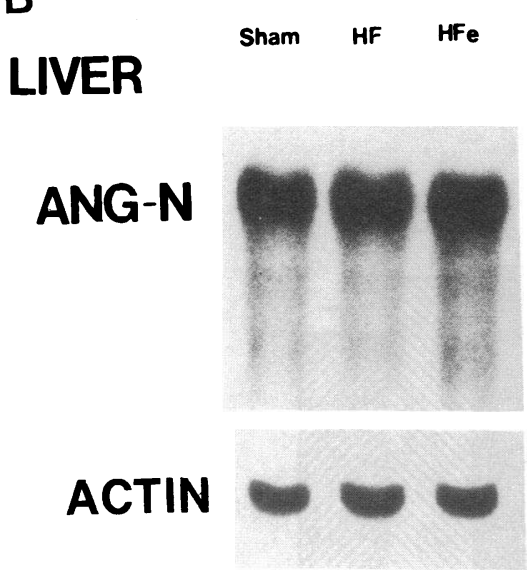

Figure 1. Representative Northern blot analysis. $(A)$ Kidney studies: Each lane contains $50 \mu \mathrm{g}$ total RNA obtained from kidneys of sham, untreated heart failure (HFv) and heart failure enalapril ( $\mathrm{HFc})$ animals, hybridized with radiolabeled $(106$ $\mathrm{cpm} / \mathrm{ml}$ hybridization mix) angiotensinogen, renin, or $\beta$-actin cDNAs, respectively, and exposed for $5 \mathrm{~d}$ to $\mathrm{x}$-ray films. As may be seen, the signal for angiotensinogen is increased in HFv rats, while the renin signal is higher in HFe rats. Expression of $\beta$-actin, in contrast, was equal in each group. $(B)$ Liver studies: Each lane contains $25 \mu \mathrm{g}$ total RNA obtained from livers, hybridized with angiotensinogen and $\beta$-actin cDNAs, and exposed for $2 \mathrm{~d}$ to $\mathrm{x}$-ray film.

levels were detectable by either Northern or slot blot analysis (Figs. 1 and 2), indicating tissue specificity of renal angiotensinogen mRNA increase. There were no significant changes in renal renin mRNA levels and renal renin concentrations in heart failure animals (Figs. 1 and 2, Table I). Indeed, the circulating components of the RAS (i.e., plasma renin, angiotensinogen, and angiotensin II ) were not different between sham and heart failure vehicle animals (Table I).

To examine if the elevated renal angiotensinogen mRNA levels in HF rats were accompanied by a parallel increase in renal angiotensin II concentrations, we studied eight $\mathrm{HF}$ and six age-matched, sham operated controls 6 wk after surgery. Renal angiotensin II concentration was $3,812 \pm 409 \mathrm{fmol} / \mathrm{g}$ wet wt, as compared with $1610 \pm 187$ in sham controls $(P<0.05)$. In parallel, the renal angiotensinogen mRNA levels in these HF rats was 1.8 -fold higher than control $(P<0.05)$. The concentrations of renal angiotensinogen $\mathrm{mRNA}$ and renal angiotensin II exhibited a positive correlation $(r=0.898, P<0.001)$ (Fig. 3). However, in these rats renal renin mRNA level was also elevated ( 1.7 -fold, $P<0.01$ ).

The average systolic blood pressure in sham operated animals was $124 \pm 2 \mathrm{mmHg} 6 \mathrm{wk}$ and $125 \pm 4 \mathrm{mmHg} 11 \mathrm{wk}$ after 


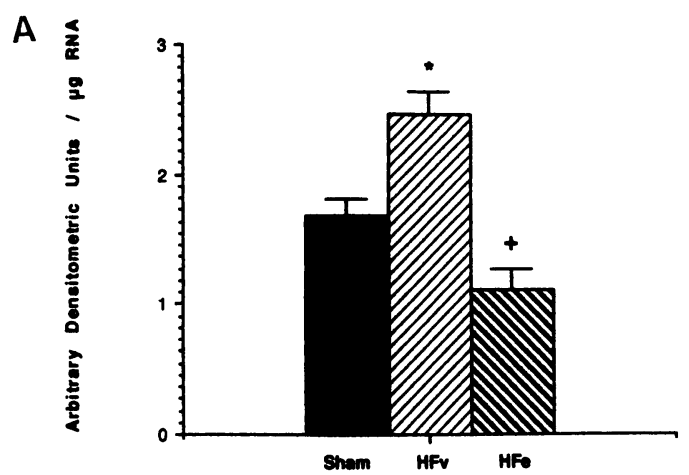

B
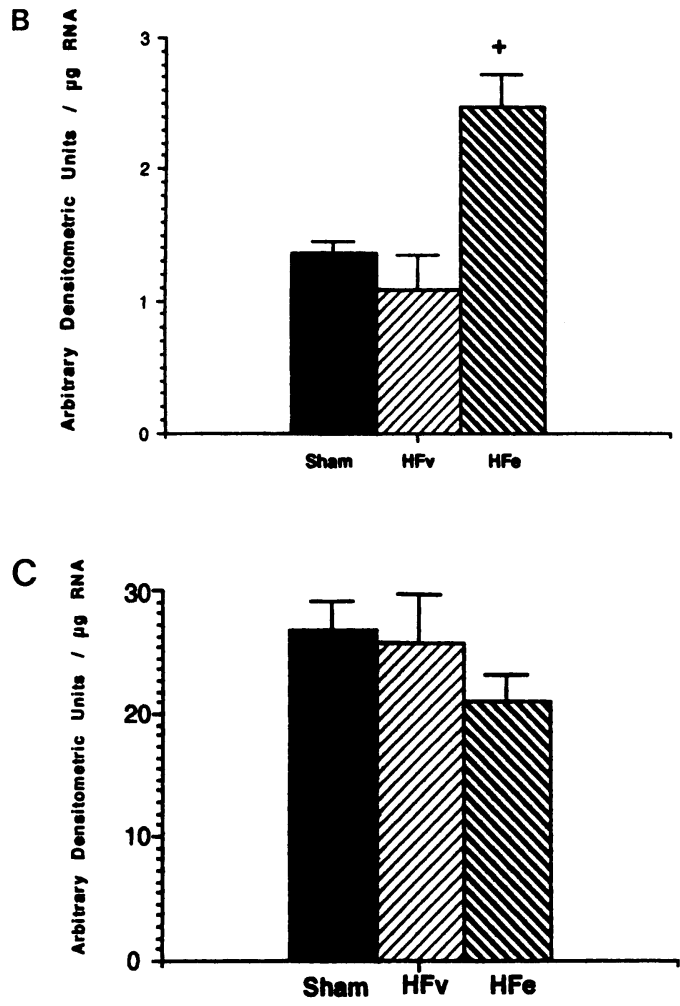

Figure 2. Quantitative data from slot blot analysis showing the effect of heart failure and enalapril treatment on renal angiotensinogen $(A)$ renin $(B)$, and hepatic angiotensinogen $(C)$ mRNA levels. mRNA levels were determined by laser densitometry of autoradiograms of multiple slot-blot analyses (see text). Data presented as mean \pm SEM. $\left({ }^{*} P=0.001\right.$ vs. sham $;+P<0.005$ vs. HFv).

the operation. In untreated heart failure animals systolic blood pressure was significantly lower ( $114 \pm 4 \mathrm{mmHg}, P=0.01$ ) after $6 \mathrm{wk}$, but was no longer statistically different from sham animals on the 11 th week of the study $(120 \pm 6 \mathrm{mmHg}, P=\mathrm{NS}$; Fig. 4). There was no significant correlation between systolic blood pressures and renal angiotensinogen mRNA levels ( $r$ $=0.09, P=\mathrm{NS}$ ).

Chronic oral enalapril treatment of HF animals for $6 \mathrm{wk}$ resulted in a significant fall in blood pressure by $11 \pm 3 \mathrm{mmHg}$ $(P<0.05$, Fig. 4$)$. Angiotensin-converting enzyme inhibition also attenuated the increase of renal angiotensinogen mRNA levels as compared with HFv animals. Thus, a significant difference in renal angiotensinogen mRNA levels was seen be-
Table I. KRC, PRC, Angiotensinogen, and Angiotensin II Concentration at 12 wk in Sham, HFv, and HFe Cohorts

\begin{tabular}{|c|c|c|c|}
\hline & Sham & HFv & $\mathrm{HFe}$ \\
\hline (ng Angiotensin $\mathrm{I} / \mathrm{h} / \mathrm{mg}$ protein) & $107 \pm 22$ & $124 \pm 45$ & $696 \pm 186^{*}$ \\
\hline (ng Angiotensin $\mathrm{I} / \mathrm{ml} / \mathrm{h}$ ) & $4.4 \pm 1.6$ & $4.6 \pm 0.5$ & $37.3 \pm 1.4^{*}$ \\
\hline $\begin{array}{l}\text { Plasma angiotensinogen } \\
\text { concentration (ng Angiotensin I }\end{array}$ & & & \\
\hline equivalent/ml) & $590 \pm 81$ & $810 \pm 42$ & $232 \pm 21^{*}$ \\
\hline $\begin{array}{l}\text { Plasma angiotensin II concentration } \\
(\mathrm{fmol} / \mathrm{ml})\end{array}$ & $32 \pm 6$ & $43 \pm 15$ & ND \\
\hline
\end{tabular}

Values are given as mean \pm SEM. $\mathrm{HFv}$, vehicle treated heart failure; $\mathrm{HFe}$, enalapril treated heart failure; ${ }^{*} P<0.005$ vs. HFv; ND, not done.

tween vehicle and enalapril treatment (Figs. 1 and 2, $P$ $<0.001)$. The average infarct size of the enalapril-treated animals was $27 \pm 3 \%$ and not statistically different from the untreated HF rat cohort. Hepatic angiotensinogen mRNA levels, on the other hand, were not altered by chronic ACE inhibition (Figs. 1 and 2). As anticipated, enalapril treatment stimulated renin mRNA levels, kidney renin, and plasma renin concentrations. Slot blot analysis demonstrated a 2.5 -fold increase in renin mRNA level during enalapril treatment $(P<0.005$, Figs. 1 and 2), and RIA showed a 5.6-fold increase in renal renin activity $(P=0.005)$ and 15.5 -fold increase in plasma renin concentration $(P<0.005)$ (Table I). $\beta$-actin mRNA levels used as internal controls were comparable in $\mathrm{HF}$ and control animals in liver and kidney, as measured by Northern (Fig. 1) and slot blots (data not shown).

\section{Discussion}

The traditional concept states that circulating angiotensin II mediates the renal hemodynamic and tubular effects of the renin angiotensin system. However, there is increasing evidence that the kidneys contain a local, functionally important intrarenal renin-angiotensin system (19) that might play a role in renal adaptation in physiological and pathophysiological states. All components of the system have been localized in the kidneys by the techniques of immunohistochemistry (18). Recent studies using Northern blot analysis have demonstrated that angiotensinogen, renin, and ACE genes are coexpressed in the kidney $(20,22,32)$. The primary localization of renin

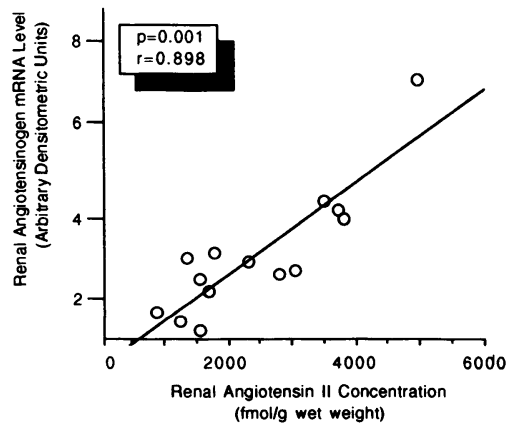

Figure 3. Regression analysis of the correlation between renal angiotensinogen mRNA level and renal angiotensin II tissue concentration. 
Blood Pressure

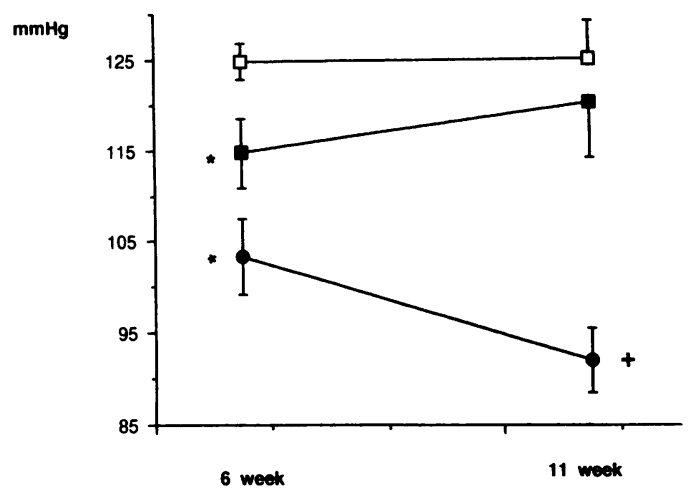

Figure 4. Systolic blood pressures at 6 and 11 wk after coronary ligation or sham operation. Open squares, sham operated animals; solid squares, untreated heart failure rats; solid circles, heart failure rats treated with enalapril at week 6 (before treatment) and week 11 (during drug treatment). Data presented as mean \pm SEM. $\left({ }^{*} P=0.01\right.$ vs. sham, $+P<0.05$ vs. HFv). $-\square-$, sham; $-\bullet-$, HFv; $-\bullet-$ HFe.

mRNA is at the vascular pole of the glomerulus (33), and angiotensinogen mRNA is mainly expressed in the proximal tubule, as shown by in situ hybridization (34). The possible intrarenal sites of angiotensin II production include the proximal tubule, the juxtaglomerular cells and the vasculature, the mesangium, and/or in the interstitial fluid. Indeed, it has recently been demonstrated that the majority of angiotensin I found in renal venous blood is of intrarenal origin (35). Evidence for predominent intrarenal production of angiotensin II has been suggested by the demonstration that angiotensin II concentrations in the renal lymph (36), and the proximal tubule (37) greatly exceeded the plasma concentrations.

A body of data suggests that the intrarenal RAS may be involved in the alterations in sodium and fluid balance observed in chronic HF via direct tubular effect or hemodynamic changes $(19,38)$. In the present study, we systematically studied the activity and expression of the circulating and intrarenal renin angiotensin system in rats with chronic HF after myocardial infarction. The model of coronary ligation in rats was selected since previous studies have documented the typical hemodynamic changes of chronic HF $(24,25)$, and decreased long-term survival in these animals (26). More importantly, in this model, there are known changes in renal function which may involve the intrarenal RAS. For example, Hostetter et al. demonstrated that rats with small to moderate size myocardial infarctions display a distinct impairment in their ability to excrete an acute sodium load, despite comparable blood pressures (27). Using the same model, Ichikawa et al. also demonstrated via micropuncture studies that rats with chronic stable experimental HF have profoundly depressed glomerular plasma flow and single nephron glomerular filtration rates, as well as elevated efferent glomerular resistance (14). Intra renal-arterial administration of an ACE inhibitor normalized these changes in HF animals, but did not influence renal function in sham control rats (14). Furthermore, the renal and hemodynamic response to atrial natriuretic peptide is impaired in this model (39), and captopril restores the renal responsiveness to ANP (40). Such findings suggest the importance of angiotensin's intrarenal effects in this HF model.
In the present study, renal angiotensinogen mRNA level increased significantly in rats with chronic HF. In the circulation, renin is the rate-limiting component of the RAS. In the kidney, renin and $A C E$ are in vast excess. Accordingly, changes in $\mathrm{KAC}$ should influence the rate of intrarenal angiotensin II production. Indeed, we demonstrated that kidney angiotensin II concentration was also elevated in HF rats and correlated with renal angiotensinogen mRNA level. Thus, our data provide evidence for the activation of the intrarenal renin angiotensin system in this experimental model of heart failure. The increase of renal angiotensinogen mRNA level was more pronounced in those animals with the largest infarcts, suggesting that the magnitude of activation of the tissue RAS system is influenced by the degree of HF. In animals with chronic HF late after myocardial infarction, there was no change in either renal renin or hepatic angiotensinogen mRNA levels, the main sources of the circulating renin angiotensin system. Indeed, circulating levels of renin and angiotensin II did not change in these chronic HF animals. Such findings confirm previous data concerning the circulating renin angiotensin system obtained in rats with coronary ligation $(10,12,41)$ and in dogs with compensated low cardiac output caused by tachycardia (11, 16), as well as in clinical studies of patients with chronic compensated $\mathrm{HF}(8,13)$.

There are several possible mechanisms responsible for the increased renal angiotensinogen mRNA in the HF rats. These include systemic and renal hemodynamic factors, increased renal sympathetic activity, and increased positive feedback effect of angiotensin II on angiotensinogen synthesis. HF rats transiently exhibited slightly lower blood pressure than sham controls and reduced renal perfusion pressure might serve as the stimulus for the increased angiotensinogen expression. However, blood pressure did not correlate with renal angiotensinogen expression; and ACE inhibitor therapy also markedly reduced blood pressure while decreasing angiotensinogen mRNA. Angiotensin II might contribute to the feedback regulation of renal angiotensinogen mRNA in heart failure. Local angiotensin II concentrations might be increased in this syndrome, and previous studies have shown that angiotensin II can stimulate hepatic angiotensinogen synthesis and expression $(42,43)$. We have demonstrated recently that renal angiotensinogen expression can be increased by high plasma levels of angiotensin II (achieved by intravenous infusion) (44). Furthermore, rats on low sodium diet for 2 wk (to stimulate the RAS) exhibit decreased renal angiotensinogen mRNA levels after administration of an ACE-inhibitor (45). However, this was not observed in rats on a normal sodium diet $(44,46)$. The results reported in the present study of heart failure rats demonstrated that ACE inhibition was associated with decreased renal angiotensinogen mRNA expression in this model. Since plasma angiotensin II levels are normal in these rats, these results suggest that increased intrarenal angiotensin II levels may be responsible, in part, for the stimulatory effects on renal angiotensinogen mRNA expression. Since systemic ACE inhibition also may improve cardiac function, renal hemodynamics, attenuate renal sympathetic activity, and decrease prostaglandin production, there are alternative mechanisms by which ACE inhibition might elicit changes in renal angiotensinogen expression.

The demonstration that renal renin mRNA levels and kidney renin concentration did not change in chronic stable HF 
rats is consistent with the finding that plasma renin concentration is normal in these rats (41). It is known that renin is upregulated by decreased renal perfusion pressure and increased sympathetic nerve activity, but downregulated by angiotensin II. Therefore, unchanged renin mRNA levels in rats with chronic stable HF might reflect the integrated and balanced response to these regulating mechanisms.

6 wk of ACE-inhibition with enalapril caused a marked increase in renal renin mRNA level (2.5-fold) and renal renin concentration (5.6-fold), as well as plasma renin concentration (15.5-fold) in these HF animals. A similar increase in renal renin mRNA was reported in normal rats after $5 \mathrm{~d}$ of ACE-inhibition (4.6 fold) (46). The mechanism of this increase is probably the removal of negative feedback by angiotensin II. This hypothesis is supported by data from animals infused with angiotensin II, in which a decrease in renal renin mRNA level was noted (44). Plasma angiotensinogen concentrations (renin substrate) decreased in the enalapril-treated HF rats because of an increased rate of degradation by elevated PRC (42).

In summary, chronic stable HF in this rat model is not associated with an activation of the circulating components of the renin angiotensin system. However, the increase in renal angiotensinogen mRNA level suggests an activation of the intrarenal renin angiotensin system, which may have functional implications in this syndrome.

\section{Acknowledgments}

The authors would like to thank Dr. Charles Sweet for assistance with cardiac histopathology, as well as Dr. Art Lage and the staff of the Harvard Animal Resource Center for animal care assistance. The angiotensinogen cDNA probe is a generous gift of Dr. Kevin Lynch, and the renin cDNA probe was generously provided by Dr. Ken Gross.

This work is supported by National Institutes of Health grants HL35610, HL-35792, HL-19259, HL-35252, HL-40210, HL-42663, and grants from the Squibb Institute for Medical Research and Parke-Davis, Warner Lambert Company. Heribert Schunkert was supported by a grant of the Deutsche Forschungsgemeinschaft (Schu 672/1-2). Alan T. Hirsch was supported by an individual National Research Search Award, F32 HL-07702-02.

\section{References} 32.

Cannon, P. J. 1977. The kidney in heart failure. N. Engl. J. Med. 296:26-

2. Paganelli, W., M. A. Creager, and V. J. Dzau. 1986. Cardiac regulation of kidney function. In International Textbook of Cardiology. T. O. Cheung, editor. Gower Publishing Co. Ltd., Aldershot, Hants, England. 918-922.

3. Watkins, L. J., J. A. Burton, E. Haber, J. R. Cant, F. M. Smith, and A. C Barger. 1976. The renin-angiotensin-aldosterone system in congestive heart failure in conscious dogs. J. Clin. Invest. 57:1606-1617.

4. DiBona, G. F. 1977. Neurogenic regulation of renal tubular sodium reabsorption. Am. J. Physiol. 233:173-181.

5. Hall, J. E., A. C. Guyton, T. E. Jackson, T. G. Coleman, T. E. Lohmeier, and N. C. Trippodo. 1977. Control of glomerular filtration rate by renin-angiotensin system. Am. J. Physiol. 233:F366-F372.

6. Schuster, V. L., J. P. Kokko, and H. R. Jacobson. 1984. Angiotensin II directly stimulates sodium transport in rabbit proximal convoluted tubules. $J$ Clin. Invest. 73:507-515.

7. Dzau, V. J. 1987. Renal and circulatory mechanisms in congestive heart failure. Kidney Int. 31:1402-1415.

8. Dzau, V. J., W. S. Colucci, N. K. Hollenberg, and G. H. Williams. 1981. Relation of renin-angiotensin-aldosterone system to clinical state in congestive heart failure. Circulation. 63:645-651.
9. Dargie, H. J., H. M. McAlpine, and J. J. Morton. 1987. Neuroendocrine activation in acute myocardial infarction. J. Cardiovasc. Pharmacol. 9(Suppl. 2):S21-S24

10. Michel, J. B., A. L. Lattion, J. L. Salzmann, M. de Yourdes Cerol, M. Philippe, J. P. Camilleri, and P. Corvol. 1988. Hormonal and cardiac effects of converting enzyme inhibition in rat myocardial infarction. Circ. Res. 62:641650 .

11. Hirsch, A. T., J. R. Cant, V. J. Dzau, and A. C. Barger. 1988. Sequential cardiorenal responses to rapid ventricular pacing in the conscious dog. FASEB (Fed. Am. Soc. Exp. Biol.) J. 2:A829 (Abstr.)

12. Hirsch, A. T., C. Talsness, A. Lage, and V. J. Dzau. 1989. The effect of experimental myocardial infarction and chronic captopril treatment on plasma and tissue angiotensin converting-enzyme activity. Clin. Res. 37:266a. (Abstr.)

13. Kubo, S. H., M. Clark, J. H. Laragh, J. S. Borer, and R. J. Cody. 1987 Identification of normal neurohormonal activity in mild congestive heart failure and stimulating effect of upright posture and diuretics. Am. J. Cardiol. 60:13221328.

14. Ichikawa, I., J. M. Pfeffer, M. A. Pfeffer, T. H. Hostetter, and B. M. Brenner B. M. 1984. Role of angiotensin II in the altered renal function of congestive heart failure. Circ. Res. 55:669-675.

15. Cleland, J. G. F., and H. J. Dargie. 1987. Heart failure, renal function, and angiotensin converting enzyme inhibitors. Kidney Int. 31(Suppl. 20):S220 S228.

16. Riegger, G. A., D. Elsner, and E. P. Kromer. 1989. Circulatory and renal control by prostaglandins and renin in low cardiac output in dogs. Am. J. Physiol. 256:H1079-H1086.

17. Levens, N. R., M. J. Peach, and R. M. Carey. 1981. Role of the intrarenal renin-angiotensin system in the control of renal function. Circ. Res. 48:157-167.

18. Taugner, R., E. Hackenthal, U. Helmchen, D. Ganten, P. Kugler, M. Marin-Grez, R. Nobiling, T. Unger, I. Lockwald, and R. Keilbach. 1981. The intrarenal renin-angiotensin system. Klin. Wochenschr. 60:1218-1222.

19. Hall, J. E. 1986. Control of sodium excretion by angiotensin II: intrarenal mechanisms and blood pressure regulation. Am. J. Physiol. 250:R960-R972.

20. Ingelfinger, J. R., R. E. Pratt, K. E. Ellison, and V. J. Dzau. 1986. Sodium regulation of angiotensinogen mRNA expression in rat kidney cortex and medulla. J. Clin. Invest. 78:1311-1315.

21. Campbell, D. J., and J. F. Habener. 1986. Angiotensinogen gene is expressed and differentially regulated in multiple tissues of the rat. J. Clin. Invest. 78:31-39.

22. Ellison, K. E., J. R. Ingelfinger, M. Pivor, and V. J. Dzau. 1989. Androgen regulation of rat renal angiotensinogen messenger RNA expression. J. Clin. Invest. 83:1941-1945.

23. Misumi, J., J. Gardes, M. F. Gonzalez, P. Corvol, and J. Menard. 1989. Angiotensinogen's role in ANG formation, renin release, and renal hemodynamics in isolated perfused kidney. Am. J. Physiol. 256(Renal Fluid Electrolyte Physiol. 25):F719-F727.

24. Braunwald, E. 1979. Myocardial infarct size and ventricular function in rats. Circ. Res. 44:503-512.

25. Fletcher, P. J., J. M. Pfeffer, M. A. Pfeffer, and E. Braunwald. 1981. Left ventricular diastolic pressure-volume relations in rats with healed myocardial infarction. Circ. Res. 49:618-626.

26. Pfeffer, M. A., J. M. Pfeffer, C. Steinberg, and P. Finn. 1985. Survival after an experimental myocardial infarction: beneficial effects of long-term therapy with captopril. Circulation. 72:406-412.

27. Hostetter, T. H., J. M. Pfeffer, M. A. Pfeffer, L. D. Dworkin, E. Braunwald, and B. M. Brenner. 1983. Cardiorenal hemodynamics and sodium excretion in rats with myocardial infarction. Am. J. Physiol. 245:H98-H103.

28. Bunag, R. D. 1973. Validation in awake rats of a tail-cuff method for measuring systolic pressure. J. Appl. Physiol. 34:279-281.

29. Bradford, M. M. 1976. A rapid and sensitive method for the quantitation of microgram quantities of protein utilizing the principle of protein dye binding. Anal. Biochem. 72:248-254.

30. Chirgwin, J. M., A. E. Pryzbyla, R. J. MacDonald, and W. J. Rutter. 1979. Isolation of biologically active ribonucleic acid from sources enriched in nuclease. Biochemistry. 18:5294-5299.

31. Sambrook, J., E. I. Fritsch, and T. Maniatis. 1989. Molecular Cloning: A Laboratory Manual. 2nd ed. Cold Spring Harbor Laboratory, Cold Spring Harbor, NY.

32. Soubrier, F., F. Alhenc-Gelas, C. Hubert, J. Allegrini, M. John, G. Tregear, and P. Corvol. 1988. Two putative active centers in human angiotensin I converting enzyme revealed by molecular cloning. Proc. Natl. Acad. Sci. USA. 85:9386-9390.

33. Deschepper, C. F., S. H. Mellon, F. Cumin, J. D. Baxter, and W. F. Ganong. 1986. Analysis by immunocytochemistry and in situ hybridization of renin and its mRNA in kidney, testis, adrenal, and pituitary of the rat. Proc. Natl. Acad. Sci. USA. 83:7552-7556.

34. Ingelfinger, J. R., W. M. Zuo, E. A. Fon, K. E. Ellison, and V. J. Dzau. 
1990. In situ hybridization evidence for angiotensinogen messenger RNA in the rat proximal tubule. J. Clin. Invest. 85:417-423.

35. Admiraal, P. J. J., F. H. M. Derkx, A. H. J. Danser, H. Pieterman, and M. A. D. H. Schalekamp. 1990. Metabolism and production of angiotensin I in different vascular beds in subjects with hypertension. Hypertension. 15:44-55.

36. Bailie, M. D., F. C. Rector, Jr., and D. W. Seldin. 1971. Angiotensin II in arterial and renal venous plasma and renal lymph in the dog. J. Clin. Invest. 50:119-126.

37. Seikaly, M. G., B. S. Arant, Jr., and F. D. Seney, Jr. 1990. Endogenous angiotensin concentrations in specific intrarenal fluid compartments of the rat. $J$. Clin. Invest. 86:1352-1357.

38. Stanton, R. C., and B. M. Brenner. 1986. Role of the kidney in congestive heart failure. Acta Med. Scand. Suppl. 707:21-25.

39. Kohzuki, M., G. P. Hodsman, and C. I. Johnston. 1989. Attenuated response to atrial natriuretic peptide in rats with myocardial infarction. Am. J. Physiol. 256(Heart Circ. Physiol. 25):H533-H538.

40. Raya, T. E., R. W. Lee, T. Westhoff, and S. Goldman. 1989. Captopril restores hemodynamic responsiveness to atrial natriuretic peptide in rats with heart failure. Circulation. 80:1886-1892.
41. Hodsman, G. P., M. Kohzuki, L. G. Howes, E. Sumithran, K. Tsunoda, and C. I. Johnston. 1988. Neurohumoral responses to chronic myocardial infarction in rats. Circulation. 78:376-381.

42. Herrmann, H. C., and V. J. Dzau. 1983. Feedback regulation of angiotensinogen production by components of the renin-angiotensin system. Circ. Res. $52: 328-334$

43. Klett, C., W. Hellmann, F. Suzuki, S. Nakanishi, H. Ohkubo, D. Ganten and $E$. Hackenthal. 1988. Induction of angiotensinogen mRNA in hepatocytes by angiotensin II and glucocorticoids. Clin. Exp. Hypertens. 10:1009-1022.

44. Schunkert, H., J. R. Ingelfinger, H. Jacob, B. Bouyounes, B. Jackson, and V. J. Dzau. 1990. Angiotensin II causes reciprocal regulation of intrarenal renin and angiotensinogen gene expression. Clin. Res. 38:443a. (Abstr.)

45. Iwao, H., K. Fukui, S. Kim, K. Nakayama, H. Ohkubo, S. Nakanishi, and Y. Abe. 1988. Sodium balance effects on renin, angiotensinogen, and atrial natriuretic polypeptide mRNA levels. Am. J. Physiol. 255:E129-E136.

46. Gomez, R. A., K. R. Lynch, R. L. Chevalier, A. D. Everett, D. W. Johns, N. Wilfong, M. J. Peach, and R. M. Carey. 1988. Renin and angiotensinogen gene expression and intrarenal renin distribution during ACE inhibition. Am. J. Physiol. 254( Renal Fluid Electrolyte Physiol. 23):F900-F906. 